\title{
UMA ANÁLISE CRIMINOLÓGICO-CRÍTICA SOBRE OS DISCURSOS DISCENTES ACERCA DA CRIMINALIZAÇÃO DA HOMOFOBIA
}

\section{A CRIMINOLOGICAL-CRITICAL ANALYSIS OF STUDENT DISCOURSES ABOUT THE CRIMINALIZATION OF HOMOPHOBIA}

\author{
Túlio Vinícius Andrade Souza ${ }^{1}$ e Maria Cristina Lopes de Almeida Amazonas² \\ 1 Universidade Federal de Pernambuco, Departamento de Pós-Graduação em Psicologia, Brasil, e- \\ mail: tulio.andrade09@gmail.com \\ 2 Universidade Católica de Pernambuco, Docente do Departamento de Psicologia, Brasil, e-mail: \\ crisamaz@gmail.com
}

ARTICLE INFO

Article history:

Received 2020-06-03

Accepted 2020-06-20

Available online 2020-06-20
Palavras-chave: Criminalização da homofobia. Criminologia Crítica. Teoria queer. Alunos do curso de Direito.

Keywords: Criminalization of homophobia. Critical criminology. Queer theory. Law students.

RESUMO. No Brasil, a sociedade está se tornando, cada vez mais, punitivista, ou seja, solicitando a aplicação do sistema penal como alternativa para reduzir a criminalidade. Essa requisição é alimentada pelo sentimento de impunidade e sensação de insegurança, frequentemente expostos pela mídia como conteúdo de exigências criminalizantes. No entanto, esse sistema reproduz mecanismos que regem a sociedade brasileira, como o machismo, a homofobia e o racismo. Diante disso, o presente trabalho buscou verificar se estudantes do último ano do curso de Direito conhecem o Projeto de Lei 122/2016 ("criminalização da homofobia") e quais posicionamentos esses sujeitos emitem sobre a citada proposta legislativa, correlacionando com a vertente teórico-epistemológica da Criminologia Crítica e suas aproximações com a teoria queer. Foi realizada, então, uma pesquisa empírica de cunho exploratório, através da aplicação de 200 questionários com estudantes do último ano da graduação em Direito de uma universidade particular de Recife. Os dados coletados foram tabulados e analisados através de uma abordagem quanti-qualitativa, demonstrando, sobretudo, que a maioria dos pesquisados não conhecia o Projeto de Lei e, ainda, resultando em categorias argumentativas importantes para a análise dos posicionamentos dos discentes. Esse estudo pode apresentar contribuições para o modelo de ensino jurídico vigente e, ainda, debates mais aprofundados no campo das implicações de movimentos criminalizadores no contexto brasileiro.

ABSTRACT. In Brazil, society is becoming increasingly punitive, that is, requesting the application of the penal system as an alternative to reduce crime. This request is fueled by the feeling of impunity and insecurity, often exposed by the media as content of criminalizing demands. However, this system reproduces mechanisms that govern Brazilian society, such as sexism, homophobia and racism. In view of this, the present work aimed to verify if students of the last year of the law course know the Bill of Law $n^{\circ}$ 122/2016 ("criminalization of homophobia") and what positions these subjects emit about this legislative proposal, correlating it with theoretical-epistemological Critical Criminology and its approximations with Queer Theory. Then, an empirical research of exploratory nature was carried out, through the application of 200 questionnaires with last years' students of the law degree at a private university in Recife. The collected data were tabulated and analyzed using a quantitative and qualitative approach, demonstrating, above all, that the majority of respondents did not know the bill of law and, still, resulting in important argumentative categories for the analysis of the students' positions. This study may present contributions to the current legal teaching model and, further, bring more in-depth debates in the field of the implications of these criminalizing movements in Brazilian context. 


\section{Introdução}

A presente pesquisa surge do desejo de entender quais os discursos produzidos pelos futuros operadores do Direito com relação à criminalização de determinadas condutas. Isso porque, partimos do pressuposto de que, no Brasil, a sociedade está se tornando, cada vez mais, punitivista, ou seja, solicitando a aplicação de um sistema penal como alternativa para reduzir a criminalidade. Essa requisição é alimentada pelo sentimento de impunidade e sensação de insegurança, frequentemente expostos pela mídia como conteúdo de exigências criminalizantes. No entanto, esse sistema reproduz mecanismos que regem a sociedade brasileira, como o machismo, a homofobia e o racismo.

Diante disso, a Criminologia Crítica questiona, enquanto perspectiva teóricoepistemológica, dentre outras coisas, se o sistema de justiça criminal promove, verdadeiramente, a contenção da criminalidade, uma de suas funções declaradas.

Nesse sentido, considerando o que foi supracitado, o objetivo dessa pesquisa é verificar se estudantes do último ano do curso de Direito conhecem o Projeto de Lei 122/2016 e quais posicionamentos esses sujeitos emitem sobre a citada proposta legislativa.

O Projeto de Lei da Câmara (PLC) número 122 de 2006 ficou conhecido como "criminalização da homofobia" ou "lei anti-homofobia" e teve autoria da Câmara dos Deputados, a partir da iniciativa da Deputada Federal lara Bernardi. O número inicial da proposta legislativa na Câmara dos Deputados era 5.003/2001 e estava inserido na esfera de assuntos sociais (direitos humanos e minorias).

Dividindo a opinião de ativistas, religiosos, juristas e civis, após mais de dez anos sem aprovação e muitas controvérsias, a situação atual é de "tramitação encerrada", de acordo com o site do Senado Federal e a explicação da ementa apresenta os seguintes termos:

Altera a Lei $n^{\circ}$ 7.716, de 5 de janeiro de 1989, o Decreto-Lei ํㅡ 2.848, de 7 de dezembro de 1940 (Código Penal) e o Decreto-Lei o 5.452, de 1ํ de maio de 1943 (Consolidação das Leis do Trabalho - CLT) para definir os crimes resultantes de discriminação ou preconceito de gênero, sexo, orientação sexual e identidade de gênero. Estabelece as tipificações e delimita as responsabilidades do ato e dos agentes. (SENADO FEDERAL, Ementa do Projeto de Lei da Câmara $n^{\circ}{ }_{122}$, 2006).

O referido Projeto de Lei da Câmara (PLC) tinha como proposta central, então, a criminalização dos preconceitos fundamentados em diversidade de orientações sexuais ou 
de identidades de gênero e, assim, previa a sua equiparação aos demais preconceitos definidos na Lei 7716/89, quais sejam: de raça ou de cor.

A Criminologia Crítica, no entanto, confronta as reinvindicações de criminalização do movimento dos direitos LGBTQI+, buscando fundamentos em outras áreas do direito penal, como as implicações da política criminal. E, mais recentemente, em uma proposta ousada, iniciou seus diálogos com a teoria queer.

Diante desse cenário, então, parece ser relevante entender o que pensam esses discentes, uma vez que serão os futuros operadores do direito e, por sua vez, deverão (ou ao menos deveriam) garantir direitos fundamentais para todas as pessoas, especificamente as populações vulneráveis e, ainda, correlacionar essas percepções com os dizeres da Criminologia Crítica queer, vertente teórica que serviu como lente para a leitura dos dados produzidos.

Os dados aqui discutidos foram apresentados no Simpósio Temático (ST 22): "Gênero e sexualidade na prisão: (des)possibilidades éticas em tempos sombrios", durante o IV Seminário Internacional Desfazendo Gênero, que aconteceu entre 13 e 15 de novembro de 2019, em Recife, Pernambuco, resultando no convite da revista REVES (Revista Relações Sociais) para publicação do manuscrito.

\section{Metodologia}

Caracteriza-se como um levantamento de campo que, de acordo com Gil (2008), desenha-se pela interrogação direta das pessoas cujo comportamento se deseja conhecer. Selltiz (1967) pontua que, em pesquisas que têm como objetivo familiarizar-se com o fenômeno ou conseguir nova compreensão do mesmo, estudos do tipo exploratório são os mais indicados. Dessa forma, então, consiste em uma pesquisa aplicada, com delineamento de estudo exploratório, que conduz a um conhecimento mais profundo a respeito do grupo de indivíduos que está sendo analisado.

\subsection{Considerações sobre o instrumento}

Nesse estudo, para atingir os objetivos previamente estabelecidos, foi construído um questionário composto por 20 questões mistas, ou seja, segundo Gil (2008), questões abertas (solicita-se aos respondentes que ofereçam suas próprias respostas), fechadas (pede-se aos respondentes para que escolham uma alternativa dentre as que são apresentadas numa lista) e uma questão dependente (quando ela só faz sentido se uma 
alternativa anterior for escolhida), tendo como ponto de partida o que foi previamente estabelecido entre os objetivos.

Dessa maneira, envolve a coleta de dados de natureza primária, que foram analisados através de uma abordagem quantitativa e qualitativa. Segundo Fachin (2003), a abordagem quantitativa é realizada por meio de uma proporção de números. Esta quantificação envolve um sistema lógico que sustenta a atribuição de números com resultados eficazes. Já a abordagem qualitativa, de acordo com Polit e Hungler (1995), envolve a coleta e análise sistemática de materiais narrativos mais subjetivos, utilizando procedimentos nos quais a tendência é um mínimo de controle imposto pelo pesquisador.

Os dados coletados foram tabulados e, quando possível, apresentados em gráficos para facilitar a análise.

\subsection{Considerações amostrais}

O universo da pesquisa são estudantes do último ano ( $9^{\circ}$ e $10^{\circ}$ semestres) da graduação do curso superior de Bacharelado em Direito de uma universidade particular, localizada em Recife/PE. E, assim, esse foi o único critério para seleção da amostra, sem maiores restrições, objetivando uma heterogeneidade entre os pesquisados.

Para determinar o tamanho de uma amostra estatisticamente válida, foi aplicada a "Fórmula para o Cálculo de Amostras para Populações Finitas", que leva em consideração o tamanho da população, ou seja, o número total de pessoas do grupo a ser estudado; a margem de erro, que é uma porcentagem que indica o nível de correspondência dos resultados do questionário com as opiniões da população total e, quanto menor a margem de erro, mais próximo o pesquisador está de ter a resposta exata a um grau de confiança específico e, por fim, o escore $z$, que é o número de desvios padrão entre determinada proporção e a média, dependendo do grau de confiança desejado. Assim, o tamanho da população correspondia a 655 estudantes que, com um nível de confiança de $95 \%$ e margem de erro de 5,78\%, implicou o total de 200 questionários aplicados e analisados.

\subsection{Aspectos éticos}

Quanto aos aspectos éticos, o projeto de pesquisa que possibilitou a coleta de dados foi aprovado pelo comitê de ética das entidades competentes. Além disso, em se tratando de uma pesquisa com seres humanos que não submete os envolvidos a riscos maiores do que os corriqueiramente oferecidos pela vivência diária, pois que os assuntos abordados no questionário dizem respeito unicamente à formação profissional dos envolvidos e as impressões deles, pode-se classificar a pesquisa como risco mínimo. 
Buscando um maior compromisso ético com os indivíduos envolvidos, todos assinaram um Termo de Consentimento Livre e Esclarecido (TCLE) concedendo sua participação na pesquisa e confirmando que foram esclarecidos sobre os objetivos pelo responsável da pesquisa, que ressaltou a possibilidade de desistir de responder ao questionário em qualquer fase do processo, sem danos ou prejuízos ao pesquisado.

Após o preenchimento e coleta, os TCLEs foram mantidos separados dos questionários para evitar qualquer possibilidade de identificação dos respondentes e estão em poder do pesquisador, tendo caráter confidencial.

\section{Resultados e Discussão}

\subsection{A análise dos dados quantitativos}

A pesquisa está inseria em um contexto onde a amostra corresponde à realidade de um curso elitista, em uma das universidades particulares de Pernambuco, com maioria branca ( $65 \%$ dos pesquisados), heterossexual ( $83 \%$ dos respondentes), autodeclarados cisgênero (100\% dos pesquisados) e cristãos (53,5\% dos respondentes). Assim, discutir temas que envolvem diversidade sexual e de gênero, nesse cenário, pode ser um potencial gerador de incômodos e inquietações. Um dado importante, também, é que a maioria corresponde ao sexo feminino $(71,5 \%)$.

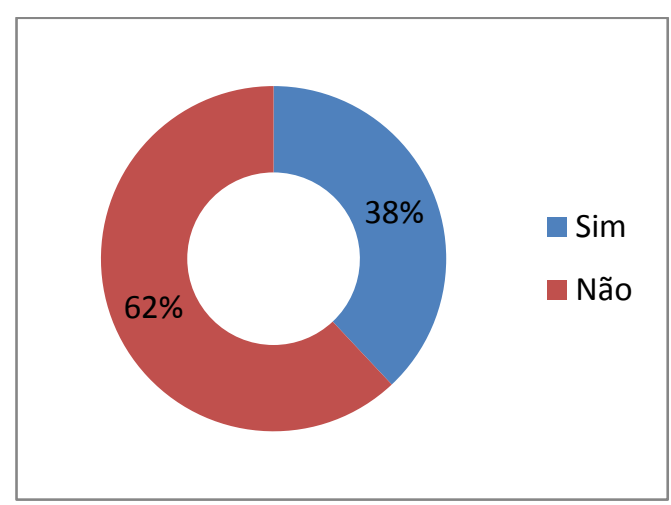

Gráfico 1 - Conhecimento dos estudantes em relação ao Projeto de Lei (PL 122/2016) Fonte: Os autores (2019)

O gráfico 1 representa se os estudantes conhecem (ou não) o Projeto de Lei em questão e corrobora a ideia de que raramente os cursos jurídicos oportunizam e/ou promovem o diálogo sobre a dinâmica social. Nesse sentido, percebe-se que a maioria dos estudantes não conhece o Projeto de Lei 122/2016 (62\% = 124 sujeitos). 
Dessa maneira, considerando que a educação tem um papel decisivo na conscientização dos indivíduos, pois os leva, através da reflexão sobre si mesmos e sobre a realidade que os circunda, a possibilidade de criar intervenções para os problemas sociais; a educação jurídica não deveria se eximir dessa responsabilidade. Isso porque, de acordo com os ensinamentos de Francischetto (2012), o Direito sendo um fato social, está continuamente na linha de tensão entre os problemas que a sociedade atravessa e a possibilidade de solucioná-los ou minorá-los. Os profissionais que lidam com esse conhecimento têm que estar conscientes de sua tarefa e o ensino jurídico crítico e reflexivo pode ser o caminho para aguçar a consciência dos estudantes, que serão os futuros profissionais.

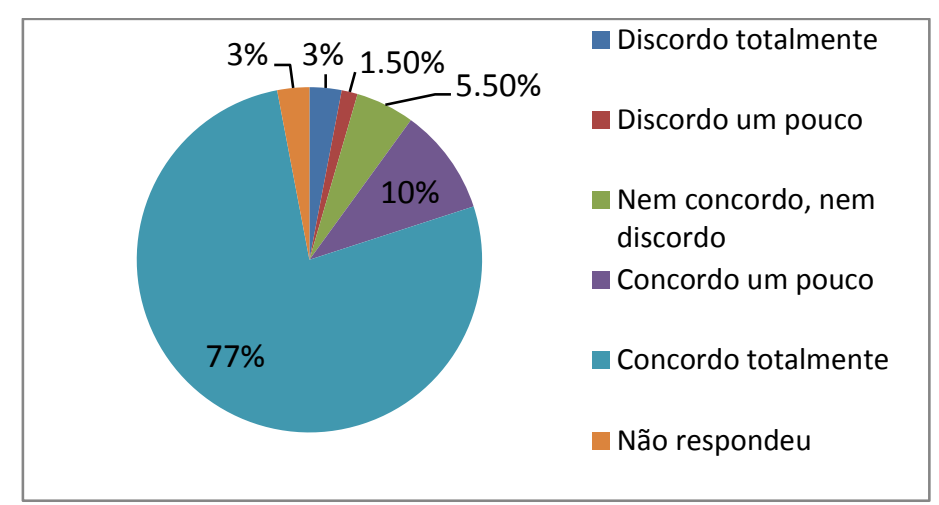

Gráfico 2 - Como os pesquisados se posicionam em relação ao Projeto de Lei (PL 122/2016)

Fonte: Os autores (2019)

O gráfico 2, por sua vez, apresenta o posicionamento dos alunos em relação ao respectivo projeto de lei mencionado e, para melhor discussão dos resultados, os dados qualitativos serão apresentados. No entanto, é possível perceber, desde logo, que a imensa maioria $(77 \%=154$ indivíduos), por mais que possam não conhecer o Projeto de Lei, concordam totalmente com os termos de sua disposição geral.

\subsection{A análise dos dados qualitativos}

Tendo em vista que a resposta às questões subjetivas era optativa, não se pode, aqui, fazer uma análise que considere as respostas de todos os indivíduos. Por isso, apenas alguns excertos foram destacados. Foram selecionados todos os fragmentos que opinavam sobre a proposta legislativa apresentada, excetuando-se aqueles que faziam comentários redundantes, de forma que depoimentos cuja observação fora feita repetidas vezes, em outros trechos, foram desconsiderados. 
Com relação à análise dos argumentos, é válido esclarecer os procedimentos que foram realizados. Nesse sentido, utilizaram-se categorias argumentativas para agrupá-los, levando em consideração a convergência da ideia central. Para isso, então, separei as justificativas colocadas nos diferentes graus de concordância, a saber: "discordo totalmente"; "discordo um pouco"; "nem concordo, nem discordo"; "concordo um pouco" e "concordo totalmente". Após esse desmembramento, utilizei como critério a ordem de frequência, ou seja, dos argumentos que mais se repetiram aos que menos se repetiram.

Como reflexo do que ocorre na sociedade, as opiniões também foram divergentes nas respostas ao questionário. Nesse sentido, o único fundamento exposto pelas pessoas que "discordam totalmente" faz alusão à existência de tipos penais que protegem a honra e, por isso, seria desnecessária a criação de tipos penais específicos, como podemos ver no seguinte trecho: "Já existem tipos penais que asseguram o bem jurídico honra no nosso Código Penal. Não vejo necessidade da criação de novos tipos penais específicos para o fim mencionado.".

Entre os sujeitos que "discordam um pouco", por sua vez, apenas um argumento também foi levantado, considerando a realidade do sistema de justiça criminal e as suas funções não declaradas, ou seja: "Mediante a realidade do sistema penal não creio que ele sirva para atingir os anseios da população LGBT, a segurança”.

Sobre isso, é possível pontuar que o Sistema de Justiça Criminal possui funções declaradas e promessas legitimadoras de sua existência, quais sejam: a proteção aos bens jurídicos e o combate à criminalidade. Todavia, existe um amplo déficit no cumprimento dessas funções declaradas. E, por isso, esse sistema tem servido apenas como mais uma forma de controle social, que já está culturalmente enraizada, de forma que segue reproduzindo ações que nutrem discriminações, desigualdades, preconceitos, seletividades e institucionalizam hierarquias (ANDRADE, 2007).

Já entre os respondentes que "não concordam, nem discordam", duas justificativas foram arroladas. A primeira delas, por ordem de repetição, está ligada ao não conhecimento de detalhes do que se está sendo discutido, a saber: "Não conheço o suficiente o projeto"; "Não conheço a integralidade do projeto" e "Preciso analisar mais detalhadamente sobre o projeto de lei para poder dar uma opinião". Além disso, foi mencionado, também, o fato da existência de previsão constitucional para discriminação, nos seguintes termos: "A Constituição Federal já fala sobre a discriminação".

As premissas exteriorizadas pelos voluntários que "concordam um pouco" também foram divididas em dois eixos. O primeiro, de pessoas que problematizam a atuação do sistema penal nesses conflitos, exemplos: "O direito penal não é o melhor instrumento, mas no primeiro momento, é necessário."; "Talvez criminalizar não seja solução, mas já ajudaria a passar para população que não seria mais tolerada tal violência.". Aqui, é possível 
observar que, apesar das desconfianças com o sistema de justiça criminal, algumas pessoas atribuem à motivação de criminalizar na urgência de se resolver um problema latente, por mais que essa solução não seja a mais adequada, na opinião deles. Aparentemente, então, percebe-se certa urgência de se encontrar respostas para diminuir os índices de violência. Por outro lado, também, ainda no primeiro eixo, alguns estudantes mencionaram a necessidade de um olhar cuidadoso para políticas de encarceramento que, segundo eles, não seria adequada, in verbis: "Acho muito importante esse projeto, porém, com ressalvas, visto que não acho que o cerceamento da liberdade seja solução"; e, ainda: "Encarceramento não seria a solução. Precisam ser educados. Concordo em criminalizar, mas não encarcerar. Aplicar uma PRD seria interessante". Nesse último fragmento, onde se lê "PRD", entenda-se "Penas Restritivas de Direitos", previstas no Código Penal brasileiro.

O segundo eixo, ainda, diz respeito aos respondentes que não sabem detalhes do projeto, ou seja: "Não sei os limites do que se configura, neste projeto, como homofobia."; "Teria que conhecer a PL inteira para emitir uma opinião mais completa".

Como a maior concentração de respondentes está entre os que "concordam totalmente", consequentemente, aqui, encontra-se também a maior quantidade de alegações que, por sua vez, foram divididas em torno de três principais argumentos.

O mais frequente deles advém de discursos que trazem a necessidade de punir como justificativa para a total concordância com o projeto. Entre esses, temos: "Lamentavelmente muitas pessoas sofrem violência por simplesmente serem homossexuais, bissexuais, travestis, transgêneros etc; e quem pratica a violência deve ser punido, tendo uma tipificação penal". No mesmo sentido, outro estudante elenca: "Porque não se deve admitir esse tipo de discriminação e o brasileiro só aprende com punição”. E, ainda, diversos outros excertos podem ser destacados, exemplos: "Acredito que quem cometer crime discriminando quem é LGBT deve ser punido de alguma forma."; "Pois homofobia deve ser considerada crime para punir os preconceituosos e agressores."; "Deve-se punir atos de discriminação com relação ao gênero ou sexo, tal como se pune o racismo e a injúria racial"; "Tendo em vista que há diversos casos diários de homofobia, precisa-se estabelecer uma punição" e, por fim, "A impunidade fragiliza as vítimas. É válido para dar seriedade ao movimento".

O cenário cultural brasileiro, por suas evidências históricas, caracteriza uma sociedade punitivista, que cada dia mais solicita a aplicação de um sistema penal como alternativa para reduzir o medo que conduz o país. Essa cobrança é intensificada pelas frequentes exposições midiáticas que expõem a criminalização como solução para vários problemas e, também, corroborada por um sentimento de impunidade e sensação de insegurança, situação denominada de Populismo Punitivo (GLOECKNER, 2011). Com isso, em uma cultura marcadamente punitivista, fica evidente o efeito simbólico da criminalização. Aliás, na maioria das vezes, o efeito simbólico é o único que a criminalização possui. É 
possível problematizar, então, a partir de um olhar criminológico, se a visibilidade proporcionada com a criminalização da homofobia, sem considerar estratégias normativas, poderia produzir um efeito simbólico virtuoso, ou seja, gerar um impacto cultural capaz de desestruturar uma cultura LGBTQlfóbica arraigada no tecido social brasileiro.

A segunda razão mais usada, por ordem de frequência, é a percepção da necessidade de atuação legislativa para trazer segurança jurídica. Para exemplificar, então, destaquei os seguintes trechos: "Em que pese a melhor solução fosse combater a discriminação com educação, a lei produz efeitos imediatos"; "O Brasil é um dos países que mais mata LGBTQs no mundo, precisamos de lei especifica SIM".

O terceiro fundamento está pautado, sobretudo, na realidade do nosso país, como também observado anteriormente. Entre estes, destaquei: "O fato de que nosso país lidera ranking's de mortes de pessoas LGBTQI+ por homofobia". E, ainda, um fragmento que merece ser mencionado faz referência ao contexto local e as possíveis implicações da criminalização: "No Brasil, a criminalização pode funcionar de forma preventiva e interventiva".

Salo de Carvalho (2017), após um vasto debate sobre as possibilidades da intersecção da "criminologia queer" com a compreensão do Direito, sobre a criminalização da homofobia, faz as seguintes observações:

Não vejo problemas de legitimidade jurídica ou de incompatibilidade com o projeto político-criminal garantista se a forma de nominação (nomen juris) do crime homofóbico ocorrer apenas através da identificação de determinadas condutas violentas já criminalizadas, isto é, a partir de um processo de adjetivação de certos crimes em decorrência da motivação preconceituosa ou discriminatória quanto à orientação sexual [...]. A técnica legislativa poderia ser restrita à identificação dessa forma de violência - sem qualquer ampliação de penas, objetivando exclusivamente dar visibilidade ao problema - através da remissão da sanção ao preceito secundário do tipo penal genérico [...]. No máximo, seguindo o caminho trilhado pela Lei Maria da Penha, a inserção da motivação homofóbica como causa de aumento de pena no rol das agravantes genéricas. (CARVALHO, 2017, p. 247).

Os dados sobre violência homofóbica, que ainda não são oficialmente regulamentados pelo governo, quando considerados junto a uma sociedade que é marcadamente punitivista, como a brasileira, fazem refletir sobre a necessidade de utilização do instrumento mais radical (ou seja, do direito penal) como caminho para proteger pessoas e grupos vulneráveis. Nesse sentido, se ponderarmos que outros movimentos sociais similares já utilizaram desse caminho, seria utópico exigir que o movimento LGBTQI+ negasse a via criminalizadora. No entanto, um dos problemas da criminalização parece ser a estratégia do movimento LGBTQI+, quando visualizada pela 
ótica político-criminal. Indispensável, então, ampliar os debates acerca da legitimidade criminológica da criminalização da homofobia.

\section{Considerações Finais}

A partir das considerações supracitadas, acredito que o caminho percorrido durante a realização da pesquisa empírica, através da aplicação e análise de questionários, é extremamente importante para que novas perspectivas sejam lançadas sobre fenômenos pouco estudados, como as implicações do ensino jurídico na formação profissional de futuros operadores do Direito.

Além disso, foi possível tabular, sintetizar e analisar os argumentos apresentados pelos sujeitos pesquisados com relação ao Projeto de Lei que ficou conhecido como "criminalização da homofobia". No entanto, esses argumentos merecem ter maiores destaques em estudos posteriores, especificamente em análises e correlações com as teorias já produzidas.

É necessário salientar, ainda, que a escassez de referenciais teóricos que discutam o presente tema indica a necessidade de estudos mais aprofundados para se chegar a conclusões mais factuais. No entanto, considerações são feitas sobre os resultados encontrados e materiais teóricos lidos, mesmo com suas limitações.

Percebe-se, então, que no cenário brasileiro, o pensamento jurídico restringe-se apenas e na maioria das vezes, ao que dizem as leis e os códigos. Isso implica, por exemplo, estudantes que não conheciam a proposta legislativa em questão, mesmo sendo de extrema relevância no contexto atual e, ainda, estabelecer possíveis paralelos de reflexo com um sistema educacional completamente tradicional e que valoriza apenas as questões técnicas.

Conhecer os argumentos dos estudantes pode ser um importante mecanismo auxiliar na propositura de outros projetos ou, ainda, na melhoria do projeto existente, com algumas modificações. É relevante, ainda, considerar a necessidade de estudos mais elaborados, que visem compreender os argumentos apresentados pelos alunos pesquisados a partir de lentes teóricas mais aprofundadas.

Com isso, é necessário repensar o modelo de criminalização que a população LGBTQI+ propõe, enquanto movimento, quando relacionada aos estudos da Criminologia, da política criminal, e suas considerações sobre seletividade. Isso porque, no Brasil, a literatura apresenta a criminalização de uma população específica e, nesse sentido, investir em movimentos criminalizadores poderia fortificar esses mecanismos de seleção e encarceramento de pessoas pobres, pretas, periféricas e mulheres, por exemplo. 


\section{Referências}

ANDRADE, Vera Regina Pereira de. A soberania patriarcal: o sistema de justiça criminal no tratamento da violência sexual contra a mulher. Direito Público. Porto Alegre, ano 5, n.17, p.52-75, jul./set. 2007.

CARVALHO, Salo de. Criminologia do preconceito: racismo e homofobia nas Ciências Criminais. São Paulo: Saraiva, 2017.

FACHIN, O. Fundamentos da Metodologia. 4르 ed. São Paulo: Saraiva, 2003.

FRANCISCHETTO, Gilsilene Passon Picoretti. A igualdade e o reconhecimento da diferença: A diversidade sexual e a formação de professores nos cursos jurídicos. In: II Seminário Nacional de Educação, Diversidade sexual e Direitos Humanos, 2012, Vitória. Anais do II Seminário Nacional de Educação, Diversidade sexual e Direitos Humanos, 2012. v. 01.

GIL, Antônio Carlos. Métodos e Técnicas de Pesquisa Social. 6 ${ }^{a}$ ed. São Paulo: Atlas, 2008.

GLOECKNER, Ricardo Jacobsen. Razões (?) do populismo punitivo. Revista Jurídica, Porto Alegre, v. 59, n. 402, p. 67-83, abr. 2011.

POLIT, D. F.; HUNGLER, B. P. - Fundamentos de pesquisa em enfermagem. $3^{\circ}$ ed., Porto Alegre, Artes Médicas, 1995. 391p.

SELLTIZ, Claire. Métodos de pesquisa nas relações sociais. São Paulo: Herder, 1967.

SENADO FEDERAL. Projeto de Lei da Câmara n ${ }^{122}$, de 2006. Altera a Lei no 7.716 , de 5 de janeiro de 1989, que define os crimes resultantes de preconceito de raça ou de cor, dá nova redação ao § 3ํ do art. 140 do Decreto-Lei nº 2.848, de 7 de dezembro de 1940 - Código Penal, e ao art. 5ำ da Consolidação das Leis do Trabalho, aprovada pelo Decreto-Lei ํo 5.452, de $1^{\circ}$ e de maio de 1943, e dá outras providências. Disponível em: < https://www25.senado.leg.br/web/atividade/materias/-/materia/79604>. Acesso em: 17 de abril de 2019. 